\title{
Fibrinogen Index in Practice
}

\author{
Elena Viktorovna Drozdova* \\ Cardiovascular Surgeon at the Samara Railway Clinical Hospital, Non-governmental Healthcare Institution, Russian Railways, Russia \\ *Corresponding author: Elena Viktorovna Drozdova, Cardiovascular Surgeon at the Samara Railway Clinical Hospital, Non- \\ governmental Healthcare Institution, Russian Railways, Russia
}

\section{Introduction}

What does it really display? There is an undisputed thesis: cancer has an often complication such as deep vein thrombosis. If cancer has factors which could be enough for the formations of clots and finally a disease - acute vein thrombosis, is it possible to identify this circumstance by the increased level of fibrinogen? And, of course, the acute period of deep vein thromboses must be the cause of hyperfibrinogenemia. To detect the significance of fibrinogen as a biochemical index of risks of thrombosis two groups of patients were selected: one group with cancer, and another one with deep vein thrombosis. So, I analyzed 100 cases (50 were diagnosed as cancer, 50 were diagnosed as deep vein thrombosis). In group 1 with acute deep vein thrombosis there were 50 patients total. With normal fibrinogen level $(2-4 \mathrm{~g} / \mathrm{l})-40$ patients. With hypofibrinogenemia - 2 patients: Patient A - with pulmonary thromboembolism, D-dimer - positive, fibrinogen - $1.4 \mathrm{~g} / \mathrm{l}$ Patient $\mathrm{B}$ - fibrinogen $1.98 \mathrm{~g} / \mathrm{l}$ (with ulcerative colitis). With fibrinogenemia - 8 patients

With the level of fibrinogen $4.1-4.9 \mathrm{~g} / \mathrm{l}-6$ patients. With the level of fibrinogen $6.270-6.8 \mathrm{~g} / \mathrm{l}-2$ patients:

Patient A - with rheumatoid arthritis, fibrinogen - $6.8 \mathrm{~g} / \mathrm{l}$. Patient B was transferred from another hospital with deep vein thrombosis after the craniotomy, fibrinogen - $6.27 \mathrm{~g} / \mathrm{l}$ (Figure 1). In group 2 with cancer there were also 50 patients total. With normal fibrinogen level (2-4 g/l) - 39 patients. With fibrinogenemia with the levels 4.1-5.3 g/l - 11 patients (Figure 2). Here is graphically displayed prevalence of normal fibrinogen index in both study groups.

\section{Result}

Bayes factor: Initially assuming that the positive reaction of the fibrinogen in cases of acute deep vein thrombosis must be at least in $80 \%$ and $50 \%$ in cases of cancer the Bayes factor is 0.2 . Consequently, it excludes the correctness of the hypotheses.

\section{Study of the level of fibrinogen}

Group 1

Total - $\mathbf{5 0}$ patients.

With normal fibrinogen level $(2-4 \mathrm{~g} / \mathrm{l}) \mathbf{- 4 0}$ patients

With fibronogenemia - 8 patients

With hypofibrinogenemia -2 patients

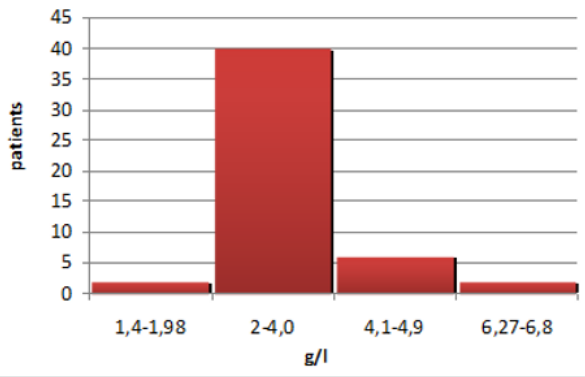

Figure 1.

\section{- Group 2}

- Total - $\mathbf{5 0}$ patients

- With normal fibrinogen level $(2-4 \mathrm{~g} / 1)-39$ patients

- With fibrinogenemia on the levels $4.1-5.3 \mathrm{~g} / 1-11$ patients

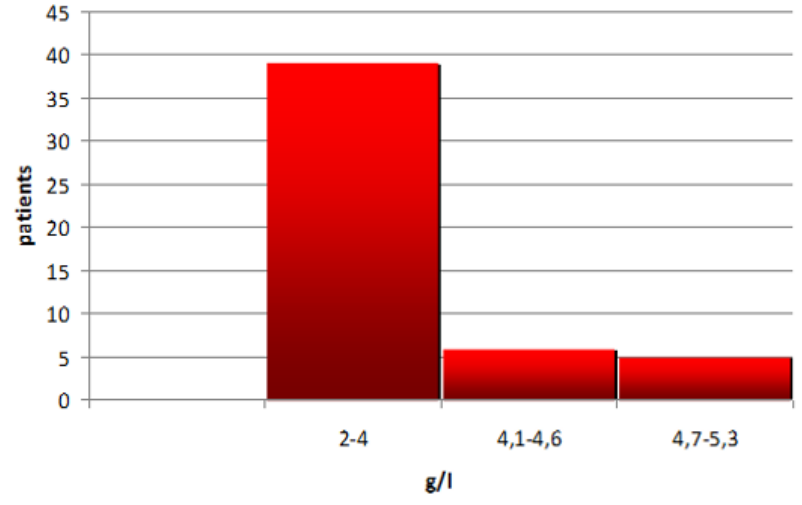

Figure 2. 


\section{Conclusion}

Despite the obvious importance of fibrinogen in the thrombogenesis, its exposure time in blood samples is probably excessively short to be a clinical index of clot formation. Fibrinogen being not only a Factor I of the blood coagulation system but also a protein of the acute phase of inflammation completely loses its clinical prognostic value. Finally, I want to say the following: modern medicine requires doctors to collect numerous analyses, tests, examinations, but a lot of them could not help us to solve any diagnostic, tactical or prognostic tasks because of their low specificity. Day by day new methods are being added to the list of mandatory research, but the relevance of the past research methods is not reconsidered. Thus, we have an accumulation of uninformative and often contradictory data which does not facilitate the work of a doctor.

Of course, we should honor the cutting-edge science of the past (such as theories of the origin and pathogenesis of cancer, thrombosis, factors of the blood coagulation system and etc.), but they must be considered constantly in regard to their specificity, sensitivity and relevance in the modern world.
To Submit Your Article Click Here: Submit Article

DOI: $10.32474 /$ SCSOAJ.2019.03.000168

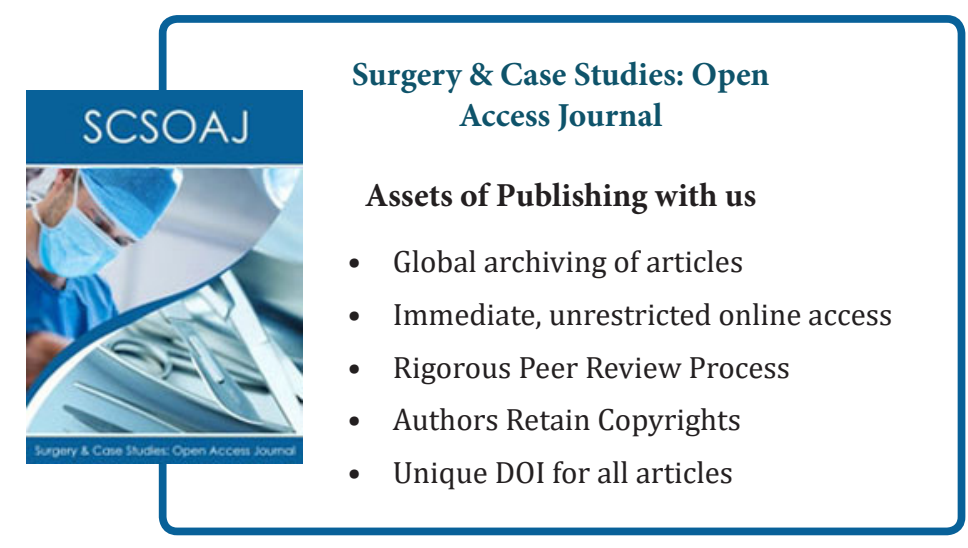

